\title{
Achados bioquímicos, eletrolíticos e hormonais de cabras acometidas com toxemia da prenhez ${ }^{1}$
}

\author{
Rodolfo J.C. Souto ${ }^{2,}$, José Augusto B. Afonso ${ }^{3 *}$, Carla L. Mendonça ${ }^{3}$, Cleyton C.D. Carvalho ${ }^{4}$, \\ Alonso P. Silva Filho ${ }^{4}$, Jobson F.P. Cajueiro ${ }^{2}$, Elizabeth H.F. Lima ${ }^{2}$ e Pierre C. Soares ${ }^{5}$
}

\begin{abstract}
Souto R.J.C., Afonso J.A.B., Mendonça C.L., Carvalho C.C.D., Alonso P. Silva Filho., Cajueiro, F.P., Lima E.H.F. \& Soares P.C. 2013. [Biochemical, electrolytic and hormonal findings in goats affected with pregnancy toxemia.] Achados bioquímicos, eletrolíticos e hormonais em cabras acometidas com toxemia da prenhez. Pesquisa Veterinária Brasileira 33(10):1174-1182. Clínica de Bovinos, Campus Garanhuns, Universidade Federal Rural de Pernambuco, Av. Bom Pastor s/n, Cx. Postal 152, Boa Vista, Garanhuns, PE 55292-270, Brazil. E-mail: afonsojab@oi.com.br

Studies on pregnancy toxemia (PT) have been constant and innovative with regard to some concepts. However, no studies have been carried out on natural clinical cases in Brazil. Thus, the aim of the present study was to perform an analysis of clinical, biochemical, electrolytic and hormonal findings in goats with PT to gain an understanding of the physiopathology of this metabolic disease. Twenty-two goats with a diagnosis of PT were analyzed at the Bovine Clinic of the Federal Rural University of Pernambuco (Garanhuns Campus, Brazil) between 2007 and 2012. Clinical exams were performed and both blood and urine were collected for the biochemical and hormonal analyses. Accentuated clinical changes were found, such as decubitus, apathy, dyspnea, increased body temperature, congested mucous membranes, dilated episcleral vessels, dehydration, anorexia, ruminal stasis and edema in the limbs. The laboratory findings revealed high concentrations of urea, creatinine, non-esterified fatty acids, $\beta$-hydroxybutyrate, amylase and cortisol as well as reductions in total proteins, albumin, total calcium, ionized calcium, phosphorus the calcium to phosphorus ratio, sodium and insulin. Fructosamine, globulin, chlorine, potassium and magnesium were within the range of normality. Regarding blood sugar, $50 \%$ of the goats were within the normal range, $27.28 \%$ were hyperglycemic and $22.72 \%$ were hypoglycemic; among the 17 animals (77.27\%) discharged with life, ten (58.82\%) had normal blood sugar levels. Five goats $(22.8 \%)$ died, $60 \%$ (3/5) of which were hyperglycemic. The mean birth rate per goat was more than two offspring. Non-esterified fatty acids were strongly associated with albumin $(r=0.60)$ and weakly associated with both $\beta$-hydroxybutyrate $(\mathrm{r}=0.10)$ and glucose $(\mathrm{r}=0.03)$. Moreover, non-esterified fatty acids were negatively associated with insulin ( $\mathrm{r}=-0.70$; strong association), cortisol ( $\mathrm{r}=-0.52$; moderate association) and amylase $(\mathrm{r}=-0.30$; moderate association). Striking clinical and metabolic alterations are found in goats with PT. The increase in certain metabolites of the energy and hormonal profile constitutes an important tool for the diagnosis and determination of the magnitude of the clinical condition in affected animals. The present data can serve as reference for future studies on nutrition and metabolism in goats with pregnancy toxemia.
\end{abstract}

INDEX TERMS: Pregnancy toxemia, clinical biochemistry, ketosis, ketones, metabolic disorder, small ruminants, goats.

\footnotetext{
${ }^{1}$ Recebido em 29 de julho de 2013.

Aceito para publicação em 19 de agosto de 2013.

${ }^{2}$ Pós-Graduando em Sanidade e Reprodução de Ruminantes, Unidade Acadêmica de Garanhuns (UAG), Universidade Federal Rural de Pernambuco (UFRPE), Av. Bom Pastor s/n, Boa Vista, Cx. Postal 152, Garanhuns, PE 55292-270, Brasil.
}

\footnotetext{
${ }^{3}$ Clínica de Bovinos, Campus Garanhuns, UFRPE, Av. Bom Pastor s/n, Boa Vista, Garanhuns, PE. *Autor para correspondência: afonsojab@oi.com.br

${ }^{4}$ Pós-Graduando em Ciência Veterinária, UFRPE, Av. Bom Pastor, s/n, Boa Vista, Cx. Postal 152, Garanhuns, PE.

${ }^{5}$ Departamento de Medicina Veterinária, UFRPE, Dois Irmãos, Recife, PE 52171-900, Brasil.
} 
RESUMO.- A abrangência dos estudos sobre a toxemia da prenhez (TP) tem sido constante e inovadora em alguns conceitos, porém o estudo dos casos clínicos naturais em cabras é inexistente no Brasil. Diante disso, realizou-se análise das alterações clínicas, do perfil bioquímico, eletrolítico e hormonal com o objetivo de compreender a fisiopatogenia da enfermidade. Foram avaliadas 22 cabras atendidas na Clínica de Bovinos, Campus Garanhuns/UFRPE, diagnosticadas com TP, no período de 2007 a 2012 . Realizou-se exame clínico e coleta de sangue e urina, para análise do perfil bioquímico e hormonal. Acentuadas alterações clínicas foram observadas, como decúbito, apatia, dispneia, aumento da temperatura corpórea, mucosas congestas, vasos episclerais injetados, desidratação, anorexia, hipomotilidade ou atonia ruminal, edema nos membros. Os resultados laboratoriais revelaram valores elevados para ureia, creatinina, ácidos graxos não esterificados (AGNE), $\beta$-hidroxibutirato, amilase e cortisol, enquanto as variáveis: proteína total, albumina, cálcio total, cálcio ionizado, fósforo, a relação cálcio e fósforo, sódio e insulina encontraram-se diminuídos. Outros parâmetros bioquímicos e eletrolíticos, como frutosamina, globulina, cloro, potássio e magnésio mantiveram-se dentro da faixa de normalidade. Quanto a glicemia, foram constatados três condições nas cabras com TP, normoglicêmicas (50\%), hiperglicêmicas $(27,28 \%)$ e hipoglicêmicas $(22,72 \%)$. Dos 17 (77,27\%) animais que obtiveram alta $10(58,82 \%)$ eram normoglicêmicos. Vieram a óbito 22,8 \% (5/22), no qual $60 \%(3 / 5)$ delas estavam hiperglicêmicas. A média de nascimento por cabra foi superior a duas crias. Verificou-se existir associação fortemente positiva dos AGNE's com a albumina $(\mathrm{r}=0,60)$, fraca com o $\beta$-hidroxibutirato $(\mathrm{r}=0,10)$ e glicose $(\mathrm{r}=0,03)$. Porém, existiu relação fortemente negativa dos AGNE's com a insulina $(r=-0,70)$, moderada com o cortisol $(r=-0,52)$ e amilase $(r=-0,30)$. Marcadas alterações clínicas e metabólicas são observadas em cabras com TP, em que o aumento de certos metabólitos do perfil energético e hormonal se torna importante ferramenta para o diagnóstico e constitui um bom instrumento para avaliar a magnitude da condição clínica dos animais enfermos. Os dados encontrados servem de referência para estudos sobre nutrição e metabolismo em cabras com TP.

TERMOS DE INDEXAÇÃO: Toxemia da prenhez, bioquímica clínica, cetose, corpos cetônicos, distúrbio metabólico, pequenos ruminantes, caprinos.

\section{INTRODUÇÃO}

A toxemia da prenhez (TP) é uma doença caracterizada por transtornos no perfil metabólico (energético e protéico) e hormonal, com maior expressão nos aspectos clínicos e nas perdas ocorridas pelas mortes dos fetos e matrizes (Smith \& Sherman 2009, Santos et al. 2011). Habitualmente, ocorre no terço final da gestação em ovelhas e cabras, acometendo geralmente fêmeas com fetos múltiplos, multíparas, estando associado ao déficit energético (Ortolani 2004, Mobini et al. 2005). A alta demanda por energia em gestações com mais de um feto, próximo ao fim da prenhez, associada a disfunção hormonal do metabolismo dos lipídios e dos carboidratos tem sido considerada como os mais importantes fatores patogênicos que culminam com o quadro de cetose clínica (Henze et al. 1998). A sua ocorrência clínica caracteriza-se por respostas terapêuticas pífias ou pouco eficientes, resultando em elevadas taxas de mortalidade, que em certas circunstâncias excedem a $80 \%$ dos animais acometidos, principalmente nos casos em que o tratamento foi realizado de forma tardia (Rook 2000, Schlumbohm \& Harmeyer 2008)

0 transtorno metabólico pode ocorrer em cabras com escore de condição corporal bom ou ruim. Porém, estudos têm mostrado maior susceptibilidade à enfermidade em animais mais velhos, gordos e fêmeas prenhes, com mais de um feto, especialmente com características produtivas superiores (Firat \& Özpinar 2002). No entanto, a sua ocorrência em animais com baixa condição corporal tem sido relatada (Cantley et al. 1991), refletindo aumento do catabolismo do tecido adiposo e de proteínas que fornecem precursores endógenos da glicose, como o glicerol e aminoácidos glicogênicos (Scott et al. 1995). As condições adversas do tempo, a qualidade do alimento e fatores de estresse ambiental podem induzir a um estado de balanço energético negativo e aumentar o risco da enfermidade (Van Saun 2000). Torna-se, portanto, um importante distúrbio metabólico de cabras, principalmente em áreas tropicais e áridas, onde os animais sofrem restrição alimentar durante os períodos secos (Cerón 1994).

Os primeiros sinais observados são: anorexia, depressão e distúrbio do comportamento que é compatível com a gravidade do caso. Muitas vezes os animais se encontram em decúbito esternal ou mesmo lateral. Podem estar presentes sinais neurológicos como: tremores, incoordenação, bruxismo e cegueira. 0 animal apresenta-se com o olhar vago e bem deprimido. Edema de membros pode estar presente, e o diagnóstico geralmente confirma-se pela detecção do aumento do teor de corpos cetonicos na urina e no sangue (Rook 2000, Borges et al. 2009, Campos et al. 2010, Santos et al. 2011).

A enfermidade, em ovelhas e cabras, está associada à hipoglicemia, hipercetonemia, redução dos níveis séricos de cálcio, sódio, potássio e magnésio como também alteração da função hepática, atribuída à lipidose hepática (Ortolani, 2004, Van Saun 2000, Brozos et al. 2011, Hefnawy et al. 2011). Como os corpos cetônicos, em especial o acetoacetato e o beta-hidróxibutirato (BHB), têm caráter muito ácido, o seu acúmulo provoca no animal um intenso quadro de acidose metabólica (2004). Outros achados como azotemia, hiperproteinemia, hipercotisolemia, hipoinsulinemia e elevação nos valores de frutosamina tem sido descritos, assim como alterações no status hematológico e imune de cabras (Andrews 1997, Bani Ismail 2008, Hefnawy et al. 2011, Santos et al. 2011).

A abrangência dos estudos sobre a TP tem sido constante e inovadora em alguns conceitos, porém são poucos os estudos dos casos clínicos naturais em cabras no Brasil e inexistentes na região Nordeste. Diante disso, realizou-se análise das alterações clínicas, do perfil bioquímico, eletrolítico e hormonal para a compreensão da fisiopatogenia da enfermidade nesta espécie. 


\section{MATERIAL E MÉTODOS}

Coleta dos dados. As informações foram colhidas dos prontuários clínicos de cabras atendidas na Clínica de Bovinos, Campus Garanhuns/UFRPE, diagnosticadas com TP, durante o período de 2007 a 2012. Incluíram-se os dados de 22 cabras criadas no estado de Pernambuco, sendo estas das raças Saanen, Anglo-nubiana, Boer e seus mestiços, com idade entre 1 e 5 anos, com peso médio de $50 \mathrm{~kg}$, submetidos a diferentes sistemas de produção, porém predominando o sistema intensivo. A maioria dos animais tinha um escore corporal médio de 3,0 e era alimentada com dieta a base de concentrados. As cabras foram submetidas ao exame ultrassonográfico para determinação do número e da viabilidade dos fetos. 0 exame clínico foi realizado segundo Smith \& Sherman (2009). Um animal veio a óbito antes que o exame clínico fosse completado, porém os dados das analises laboratoriais foram utilizados.

Colheita das amostras. Amostras de sangue foram coletadas por venopunção jugular, com agulha 25x8mm em tubos siliconizados vacutainer e centrifugadas ${ }^{6}$ a $3500 \mathrm{rpm}$ por cinco minutos, com anticoagulante fluoreto de sódio/oxalato para obtenção de plasma e determinação da glicose. As amostras obtidas em tubos sem anticoagulante, para obtenção do soro, foram empregadas nas análises bioquímicas e hormonais. As amostras foram condicionadas sob a forma de alíquotas de soro e plasma em tubos tipo eppendorf e armazenadas em ultra freezer à temperatura de $-80^{\circ}$ $\mathrm{C}^{7}$.

Análises laboratoriais. Os componentes avaliados foram: proteínas totais $^{8}$, albumina ${ }^{8}$, ureia $\mathrm{CE}^{8}$, creatinina $^{8}$, frutosamina ${ }^{8}$, amilase CNPG, cálcio liquiform (cálcio total) ${ }^{8}$, fósforo UV liquiform $^{8}$, magnésio ${ }^{8}$ e cloretos ${ }^{8}$ feitas em analisador bioquímico semi-automático LabQuest ${ }^{8}$ com uso de reagentes comerciais ${ }^{8}$. Determinaram-se os íons sódio ${ }^{9}$ e potássio ${ }^{9}$ mediante fotometria de chama ${ }^{9}$. Os valores de globulina foram obtidos por meio de subtração entre o valor da proteína total e albumina, o Ca ionizado através do emprego de cálculo envolvendo o valor da albumina, proteína total e o cálcio total (seguindo metodologia empregada pelo fabricante - doles $^{10}$ ), e a relação cálcio: fósforo (Ca: P) dividindo-se o valor do cálcio total pelo valor do fósforo. Os ácidos graxos não esterificados (AGNE) e $\beta$-hidroxibutirato (BHB) foram determinados de acordo com os reagentes comerciais (Randox Laboratories Ltd) ${ }^{11}$ e para as determinações hormonais de cortisol e insulina, foi empregada a técnica da electroquimioluminecência ${ }^{12}$ empregado-se reagentes comerciais (Cobas ${ }^{\circledR}$ ). A urina após ter sido coletada por meio de micção espontânea, teve a pesquisa de corpos cetônicos realizada com o emprego de fitas reagentes para a urinálise (Dirksen 1993).

Análise estatística. Os dados foram processados considerando-se medidas de tendência central e frequências absoluta e relativa. Efetuou-se análise de associação entre pares de variáveis

\footnotetext{
${ }^{6}$ Centrifuga Fanem Ltda Baby I, Mod. 206, Av. General Ataliba Leonel 1790, São Paulo, SP, Brasil.

${ }^{7}$ Ultralow freezer NuAire Inc., 2100 Fernbrook Lane N. Plymouth, MN 55447, USA.

${ }^{8}$ Labtest Diagnóstica S.A., Av. Paulo Ferreira da Costa 600, Lagoa Santa, MG 33400-000, Brasil.

${ }^{9}$ Benfer - Produtos para Laboratórios, Rua Padre Agostinho Poncet 74, São Paulo, SP 02408- 040.

${ }^{10}$ Doles, Rodovia BR 153 Km 493, Lote 7, Chácara Retiro, Goiânia, GO 74665-833, Brasil.

${ }^{11}$ Randox Laboratories Ltd, Ardmore, Diamond Road, Crumlin, Antrim, BT 29 4QY, UK

${ }^{12}$ Cobas e 411 - Roche Sistemas de Diagnósticos, Lda, Av. Eng. Billings 1729, Jaguaré, SP 05321- 900.
}

com a determinação do coeficiente de correlação de Pearson. A significância obtida na correlação foi feita segundo Little \& Hills (1978). Os dados foram analisados por meio do programa computacional Statistical Analysis System (SAS 2009).

Aprovação no comitê de ética. 0 trabalho obteve parecer favorável da Comissão de Ética no Uso de Animais (CEUA) da Universidade Federal Rural de Pernambuco, atendendo às normas éticas, conforme estabelecidas na legislação vigente e no regimento interno da CEUA/UFRPE, de acordo com a resolução 024/2012 do CEPE/UFRPE ou estando de acordo com as normas sugeridas pelo COBEA e com as normas internacionais estabelecidas pelo National Institute of Health Guide for Care and Use of Laboratory Animals.

\section{RESULTADOS}

As alterações clínicas mais evidentes apresentadas pelas cabras foram decúbito em 38,10\% (8/21) dos casos, apatia em 38,10\% (8/21), dispneia em 52,38\% (11/21), 23,81\% (5/21) apresentaram aumento da temperatura corpórea, as mucosas estavam congestas em 47,62\% (10/21), assim como os vasos episclerais injetados em 76,20\% (16/21), o grau de desidratação de moderado a grave correspondendo a 47,62\% (10/21) dos casos, 57,15\% (12/21) apresentavam ausência parcial ou total do apetite, diminuição da

Quadro 1. Principais sinais clínicos observados em cabras acometidas com toxemia da prenhez, atendidas na Clínica de Bovinos, Campus Garanhuns, UFRPE, entre 2007 e 2012

\begin{tabular}{|c|c|c|c|}
\hline \multirow[t]{2}{*}{ Características } & \multirow[t]{2}{*}{$\begin{array}{l}\text { Achados } \\
\text { clínicos }\end{array}$} & \multicolumn{2}{|c|}{$\begin{array}{l}\text { Número de } \\
\text { animais }\end{array}$} \\
\hline & & $\mathrm{FA}^{*}$ & $\mathrm{FR}^{* *}(\%)$ \\
\hline \multirow[t]{2}{*}{ Atitude } & Estação & 13 & 61,90 \\
\hline & Decúbito & 8 & 38,10 \\
\hline \multirow[t]{2}{*}{ Comportamento } & Sem alteração & 13 & 61,90 \\
\hline & Apático & 8 & 38,10 \\
\hline \multirow[t]{4}{*}{ Escore corporal } & 1 & 1 & 4,76 \\
\hline & 2 & 2 & 9,53 \\
\hline & 3 & 11 & 52,38 \\
\hline & 4 & 7 & 33,33 \\
\hline \multirow[t]{2}{*}{ Temperatura corpórea } & $<39,5^{\circ} \mathrm{C}$ & 16 & 76,19 \\
\hline & $\geq 39,5^{\circ} \mathrm{C}$ & 5 & 23,81 \\
\hline \multirow[t]{3}{*}{ Mucosas } & Congestas & 10 & 47,62 \\
\hline & Rosadas & 8 & 38,10 \\
\hline & Rosa-pálido & 3 & 14,28 \\
\hline \multirow[t]{4}{*}{ Grau de desidratação } & Ausente & 3 & 14,28 \\
\hline & Leve & 8 & 38,09 \\
\hline & Moderado & 9 & 42,86 \\
\hline & Grave & 1 & 4,76 \\
\hline \multirow[t]{3}{*}{ Edema nos membros } & Ausente & 13 & 61,90 \\
\hline & Membros posteriores & 2 & 9,52 \\
\hline & Nos quatro membros & 6 & 28,57 \\
\hline \multirow{2}{*}{ Claudicação } & Ausente & 20 & 95,23 \\
\hline & Presente & 1 & 4,77 \\
\hline \multirow[t]{3}{*}{ Preenchimento dos vasos episclerais } & is Sem alterações & 3 & 14,28 \\
\hline & Injetados & 16 & 76,20 \\
\hline & Vazios & 2 & 9,52 \\
\hline \multirow[t]{2}{*}{ Dispnéia } & Ausente & 10 & 47,62 \\
\hline & Presente & 11 & 52,38 \\
\hline \multirow[t]{3}{*}{ Motilidade ruminal } & Sem alteração & 4 & 19,04 \\
\hline & Diminuído & 15 & 71,43 \\
\hline & Ausente & 2 & 9,53 \\
\hline \multirow[t]{3}{*}{ Apetite } & Presente & 9 & 42,85 \\
\hline & Caprichoso & 5 & 23,82 \\
\hline & Ausente & 7 & 33,33 \\
\hline
\end{tabular}

$\bar{*} \mathrm{FA}=$ Frequência absoluta, ${ }^{* *} \mathrm{FR}=$ Frequência relativa. 
motilidade do rúmen ou atonia ruminal foi observada em $80,96 \%$ das situações $(17 / 21)$ e edema nos membros, tanto dos posteriores como dos anteriores em 38,09\% (8/21) (Quadro 1). A evolução clínica nos animais que recebeu alta foi de 14 dias, enquanto os animais que vieram a óbito apresentaram evolução de 10 dias.

Quanto a glicemia, 50\% das cabras com TP eram normoglicêmicas, 27,28\% hiperglicêmicas, enquanto apenas $22,72 \%$ eram hipoglicêmicas. Dos 17 (77,27\%) animais que obtiveram alta $10(58,82 \%)$ eram normoglicêmicos. Vieram a óbito $22,8 \%(5 / 22)$, no qual $60 \%(3 / 5)$ delas estavam hiperglicêmicas. A média de nascimento por cabra foi superior a duas crias (Quadro 2).

Quadro 2. Valores médios e desvios padrão $(x \pm s)$ do perfil glicêmico (mmol/L), número de animais, número de crias e desfecho clínico de cabras acometidas com Toxemia da Prenhez, UFRPE, atendidas na Clínica de Bovinos entre os anos de 2007 e 2012

\begin{tabular}{lccccc}
\hline Condição clínica & $\begin{array}{c}\text { Glicemia } \\
\text { (mmol/L) }\end{array}$ & $\begin{array}{c}\text { Número de } \\
\text { animais }\end{array}$ & $\begin{array}{c}\text { Número } \\
\text { de crias }\end{array}$ & \multicolumn{2}{c}{ Desfecho } \\
\cline { 5 - 6 } & Alta & Morte \\
\hline Hipoglicêmicas & $2,23 \pm 0,49$ & $5(22,72 \%)$ & $11(2,2)$ & 4 & 1 \\
Normoglicêmicas & $3,44 \pm 0,44$ & $11(50,00 \%)$ & $24(2,18)$ & 10 & 1 \\
Hiperglicêmicas & $6,08 \pm 1,12$ & $6(27,28 \%)$ & $14(2,33)$ & 3 & 3
\end{tabular}

Os resultados laboratoriais revelaram valores elevados para: ureia, creatinina, AGNE, BHB, amilase e cortisol, enquanto as variáveis: proteína total, albumina, cálcio total, cálcio ionizado, fósforo, $\mathrm{Ca}$ : $\mathrm{P}$, sódio e insulina encontraram-se com valores abaixo dos valores de referência para a espécie. Outros parâmetros bioquímicos e eletrolíticos, como globulina, cloro, potássio e magnésio mantiveram-

Quadro 3. Valores médios, desvios padrão $(x \pm s)$, mínimos e máximos dos parâmetros bioquímicos (proteicos), em cabras acometidas com toxemia da prenhez, atendidas na Clínica de Bovinos, Campus Garanhuns, UFRPE, entre 2007 e 2012

\begin{tabular}{lrrrrc}
\hline \multicolumn{1}{c}{ Parâmetros } & Média & s & Mínimo & Máximo & $\begin{array}{c}\text { Valores de } \\
\text { referência* }\end{array}$ \\
\hline Creatinina (mg/dL) & 1,67 & 0,98 & 0,52 & 3,57 & $0,71 \pm 0,06^{\mathrm{a}}$ \\
Ureia (mmol/L) & 7,39 & 3,47 & 2,77 & 16,55 & $3,57-7,14^{\mathrm{b}}$ \\
Proteína Total (g/L) & 60,81 & 11,28 & 42,90 & 85,50 & $64-70^{\mathrm{b}}$ \\
Albumina (g/L) & 22,04 & 5,43 & 12,10 & 36,50 & $27-39^{\mathrm{b}}$ \\
Globulina (g/L) & 38,77 & 8,58 & 24,90 & 55,00 & $27-41^{\mathrm{b}}$ \\
\hline
\end{tabular}

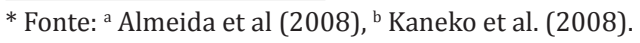

Quadro 4. Valores médios, desvios padrão $(x \pm s)$, mínimos e máximos dos parâmetros bioquímicos (energéticos), em cabras acometidas com toxemia da prenhez, atendidas na Clínica de Bovinos, Campus Garanhuns, UFRPE, entre 2007 e 2012

\begin{tabular}{lccccc}
\hline Parâmetros & Média & $\mathrm{s}$ & Mínimo & Máximo & $\begin{array}{c}\text { Valores de } \\
\text { referência* }\end{array}$ \\
\hline Glicose $(\mathrm{mmol} / \mathrm{L})$ & 3,89 & 1,61 & 1,40 & 7,21 & $2,78-4,16^{\mathrm{b}}$ \\
Frutosamina $(\mu \mathrm{mol} / \mathrm{L})$ & 170,10 & 31,20 & 106,31 & 242,42 & $172 \pm 0,2^{\mathrm{c}}$ \\
AGNE $(\mathrm{mmol} / \mathrm{L})$ & 1,02 & 0,45 & 0,24 & 1,78 & $0,4 \pm 0,2^{\mathrm{d}}$ \\
$\beta$-Hidroxibutirato (mmol/L) & 2,93 & 2,94 & 0,26 & 9,39 & $\leq 0,86^{\mathrm{e}}$ \\
Amilase (U/L) & 50,48 & 15,66 & 31,62 & 79,06 & $7,76-11,5^{\mathrm{f}}$
\end{tabular}

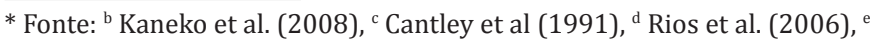
Bani Ismail et al. 2008, ${ }^{\mathrm{f}}$ Araújo e Silva (2008).
Quadro 5. Valores médios, desvios padrão $(\mathrm{x} \pm \mathrm{s})$, mínimos $\mathrm{e}$ máximos dos parâmetros minerais, em cabras acometidas com toxemia da prenhez, atendidas na Clínica de Bovinos, Campus Garanhuns, UFRPE, entre 2007 e 2012

\begin{tabular}{lccccc}
\hline Parâmetros & Média & s & Mínimo & Máximo & $\begin{array}{c}\text { Valores de } \\
\text { referência* }\end{array}$ \\
\hline Ca Total (mmol/L) & 1,70 & 0,71 & 0,29 & 2,59 & $2,23-2,93^{\mathrm{b}}$ \\
Ca Ionizado (mmol/L) & 1,07 & 0,48 & 0,15 & 1,90 & $1,31-1,52^{\mathrm{b}}$ \\
$\mathrm{Ca}: \mathrm{P}(\mathrm{mmol} / \mathrm{L})$ & 0,92 & 0,44 & 0,11 & 1,99 & $1,4: 1-1,6: 1^{\mathrm{h}}$ \\
$\mathrm{P}(\mathrm{mmol} / \mathrm{L})$ & 2,04 & 0,73 & 0,68 & 3,57 & $2,39 \pm 0,42^{\mathrm{h}}$ \\
$\mathrm{Mg}(\mathrm{mmol} / \mathrm{L})$ & 0,99 & 0,34 & 0,36 & 1,73 & $0,31-1,48^{\mathrm{b}}$ \\
$\mathrm{Na}(\mathrm{mmol} / \mathrm{L})$ & 130,10 & 9,88 & 113,00 & 148,00 & $142-155^{\mathrm{b}}$ \\
$\mathrm{K}(\mathrm{mmol} / \mathrm{L})$ & 3,66 & 0,63 & 2,50 & 4,70 & $3,5-6,7^{\mathrm{b}}$ \\
$\mathrm{Cl}(\mathrm{mmol} / \mathrm{L})$ & 108,44 & 5,25 & 99,23 & 117,20 & $99-110,3^{\mathrm{b}}$
\end{tabular}

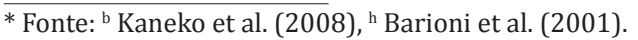

Quadro 6. Valores médios, desvios padrão ( $\mathrm{x} \pm \mathrm{s})$, mínimos e máximos dos parâmetros hormonais, em cabras acometidas com toxemia da prenhez, atendidas na Clínica de Bovinos, Campus Garanhuns, UFRPE, entre 2007 e 2012

\begin{tabular}{lccccc}
\hline Parâmetros & Média & s & Mínimo & Máximo & $\begin{array}{c}\text { Valores de } \\
\text { referência* }\end{array}$ \\
\hline Insulina (pmol/L) & 45,85 & 22,80 & 21,15 & 94,46 & $78,2 \pm 1,45^{g}$ \\
Cortisol (nmol/l) & 92,30 & 96,46 & 2,99 & 12,92 & $65 \pm 8^{1}$
\end{tabular}

* Fonte: ${ }^{\mathrm{b}}$ Kaneko et al. (2008), ${ }^{\mathrm{g}}$ Hefnawy et al. (2011).

-se dentro da faixa de normalidade (Quadros 3-6). Todos os animais acometidos pela enfermidade apresentaram cetonúria, porém com diferentes graus de intensidade na fita reagente.

As correlações entre a concentração sanguínea de AGNE com a albumina, o BHB e a glicose foram de 0,60, 0,10 e 0,03, respectivamente (Fig.1). Porém existiram correlações negativas de AGNE com insulina $(r=-0,70)$, com o cortisol $(r=-0,52)$ e com a amilase $(r=-0,30)$. Uma correlação moderadamente positiva foi observada entre a insulina com Ca total ( $\mathrm{r}=0,51)$ e Ca ionizável $(\mathrm{r}=0,52)$ (Fig.1).

\section{DISCUSSÃO}

As manifestações clínicas encontradas nas cabras acometidas com TP são condizentes com as relatadas por Mobini et al. (2005), Barakat et al. (2007), Smith \& Sherman (2009), Hefnawy et al. (2011) que se depararam com animais apresentando quadros clínicos semelhantes. A evolução clínica mais longa para os pacientes que obtiveram alta se deve provavelmente a intervenção terapêutica mais precoce diante dos sinais clínicos de TP apresentados, o que segundo Rook (2000) e Campos et al. (2010) evita a evolução da doença e o consequente agravamento e óbito, tanto da fêmea como de suas crias. A maioria das fêmeas que vieram a óbito era hiperglicêmica, refletindo o grau de estresse em função da gravidade do caso.

A redução nos níveis de albumina encontrados pode ser justificada pela ocorrência de uma falha hepática ou renal como consequência do quadro de TP, como relatado por Yarim \& Ciftci (2009) em ovelhas. Barakat et al. (2011) e Hefnawy et al. (2011) em cabras, relataram que a sua síntese ocorre no fígado, e segundo González et al. (2009) a sua diminuição pode está presente em situações onde existe 

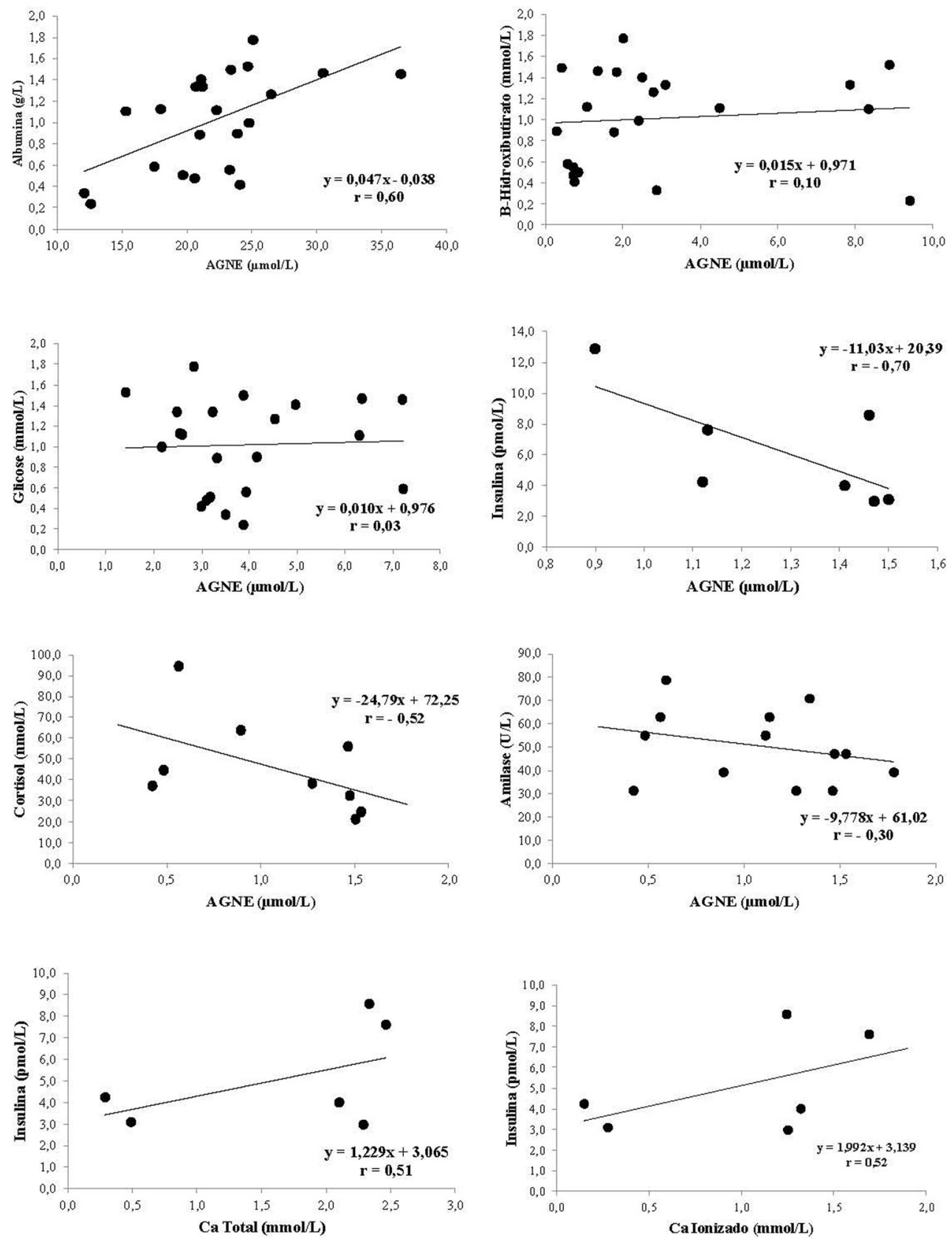

Fig.1. Representação gráfica da relação entre variáveis do perfil metabólico em cabras com toxemia da prenhez.

infiltração gordurosa em animais com alta lipomobilização, podendo ser um indicador da funcionalidade hepática. No entanto, Santos et al. (2011) estudando casos espontâneos de TP em ovelhas, constataram não haver alteração em relação aos índices de normalidade estabelecidos para a espécie, assim como González et al. (2011b) após induzir a TP em cabras.

A elevação sanguínea da ureia e creatinina caracterizando um quadro de azotemia podem está relacionada à diminuição da taxa de filtração glomerular e consequente redução na excreção urinária desse composto. A elevação na concentração de ureia foi observada por Barakat et al. (2007), Bani Ismail et al. (2008) em cabras com TP. Já Hefnawy et al. (2011) observaram o aumento das duas variáveis nas cabras acometidas, assim como Yarim \& Ciftcti (2009) e Santos et al. (2011) em ovelhas com TP. No entanto, Moghaddam \& Hassanpour (2008), observaram elevação da concentração de ureia em ovelhas em final de gestação e a relacionou ao aumento do metabolismo proteico durante a prenhez ou devido ao manejo nutricional empregado, ressaltando a importância da monitoração nesse período para a redução da ocorrência da TP subclínica. Ainda, de acordo com Santos et al. (2011), teores elevados de ureia e de creatinina são indicativos de um quadro de insuficiência renal, que pode ser severo no estágio terminal e está associado com o prognóstico reservado, fortalecendo os achados de Parry \& Taylor (1956) e Hefnawy et al. (2011) que demonstraram haver um considerável prejuízo da função renal em 
ovelhas e cabras com TP. Mas, para González \& Silva (2006), a ureia, apesar de ser um indicador do funcionamento renal, em ruminantes não constitui o mais adequado componente desta, em função do alto grau de reciclagem deste metabólito entre o sangue e o rúmen. Os níveis de creatinina podem ser interpretados de forma mais adequada para esta função na espécie em estudo, similar aos de ureia no tocante a taxa de filtração renal.

O aumento nas concentrações dos AGNE`s se deu em virtude da lipólise que acontece durante o estado de balanço energético negativo (BEN), apresentado em função da alta demanda por energia nas últimas semanas de gestação devido ao rápido aumento do crescimento dos fetos. Barakat et al. (2007), também observaram acentuada elevação desta variável em cabras como resposta a maior demanda de substratos endógenos para a produção de energia durante a gestação, assim como foi constatado por Cal et al. (2009) em ovelhas acometidas por esse distúrbio. No entanto, Sargirson et al. (1994) e Harmeyer \& Schlumbohm (2006), observaram que a elevação da concentração plasmática de AGNE's não foi um achado consistente em ovelhas com TP. Tal condição foi abordada por González et al. (2011), considerando os níveis de $\beta$-hidroxibutirato mais sensíveis para detectar estágios de cetose subclínica do que AGNE's em vacas leiteiras de alta produção com alto grau de lipomobilização. Destacou que a alta lipomobilização não necessariamente irá implicar em cetose. A alta correlação positiva encontrada entre os valores de AGNE's e de albumina justifica-se porque esta será responsável pelo transporte dos AGNE`s na corrente sanguínea e a sua saturação provocada em virtude do aumento da lipólise e rápida liberação de AGNE`s a partir do tecido adiposo reduz a afinidade da albumina a essas moléculas impedindo a liberação de mais ácidos graxos com consequente acúmulo dentro do adipócito (Metz et al. 1973).

Quanto ao BHB, sua elevação reafirma uma condição de balanço energético negativo, já que associado com AGNE's são os principais indicadores de lipomobilização em ruminantes, e por ser o mais importante e abundante corpo cetônico. Em situações normais os corpos cetônicos estão em baixas quantidades no plasma, mas em situações onde há deficiência de energia somada à existência de uma boa reserva de lipídeos, ocorre o processo conhecido como lipomobilização, nesta condição há uma grande quantidade de AGNE's liberada para o sangue, que devem ser oxidados e quando em excesso, gera muitos corpos cetônicos (González et al. 2000). A hipercetonemia verificada é uma característica comum da doença em cabras e ovelhas, entretanto Harmeyer \& Schlumbohm (2006) relataram que esta condição não representa apenas um sinal da enfermidade, mas atua de maneira multifuncional em promover o desenvolvimento da TP. Tal fato foi justificado pela reduzida habilidade de ovelhas multíparas em final de gestação em utilizar corpos cetônicos, o que demonstra haver uma grande importância deste componente na patogênese dessa desordem metabólica.

Os níveis séricos de glicose obtidos foram semelhantes aos encontrados por Henze et al (1998), Barakat et al. (2007), Campos et al. (2010) e Santos et al.(2011), por que não encontraram apenas uma condição de glicemia, mas três estados glicêmicos nas cabras e ovelhas acometidas com TP. Entretanto, diferem dos relatos de Bani Ismail et al. (2008) e Hefnawy et al. (2011) que encontraram apenas o estado hipoglicêmico nas cabras com TP. Lima et al. (2012) reportam a importância da análise do perfil glicêmico nos últimos dias de gestação, considerando que a glicemia em cabras gestantes com TP pode ser um bom indicador da viabilidade dos fetos, reiterando a condição de gravidade nas cabras no estado de hiperglicemia, enquanto que no estado hipoglicêmico resultou num resultado terapêutico (cesariana) mais favorável. Tal informação é de extrema importância para a adoção quanto à instituição de protocolos terapêuticos, principalmente quanto à administração de glicose por via parenteral em animais enfermos.

Estes estados glicêmicos encontrados são justificados quando a diminuição da concentração de glicose plasmática é concomitante à redução da renovação da glicose em ovelhas gestantes, o que as torna mais sensíveis a TP, o que pode explicar porque a enfermidade ocorre quase que exclusivamente em multíparas no final da gestação; e quanto à condição de hiperglicemia constatada pode ser explicada, em algumas situações, pela condição de estresse presente nos animais devido à elevação dos índices de cortisol, que tem características gliconeogênicas, associada à sua ação inibitória à insulina, interferindo nos receptores periféricos a sua utilização e posterior glicólise (Basset et al. 1966; Schlumbohm \& Harmeyer 2008).

Os valores de frutosamina dentro dos parâmetros de normalidade justificam-se porque as cabras com TP em estudo encontram-se em sua maioria em uma fase normoglicêmica. Esse achado acompanha a lógica dos resultados encontrados por Cantley et al. (1991), que observaram ovelhas clinicamente afetadas apresentando marcada diminuição da concentração sérica de frutosamina, sugerindo uma persistente hipoglicemia, e dos encontrados por Santos et al. (2011), que obtiveram valores elevados como consequência do quadro de hiperglicemia observado em um número expressivo de animais. Tal achado chama a atenção para a investigação quanto ao valor diagnóstico da frutosamina quanto à homeostase da glicose nesta espécie, quando acometida com a TP.

Devido à importância da glicose no metabolismo intermediário e de sua relação com aminoácidos e o metabolismo lipídico, a sua mensuração pode ser também uma útil ferramenta, associada a outros componentes, para monitorar a saúde e o status metabólico. Uma vez que, a mensuração única da glicose somente mostra a concentração momentânea, que está sujeita à rápida e frequente mudança, dependentes de variações diárias, dietéticas e fatores individuais. Na medicina humana, a mensuração de produtos como a proteínas glicadas sanguíneas (HbA1c e frutosamina) tem sido estabelecidas como um indicador de glicemia durante um longo período de tempo. Estes metabólitos, uma vez formados, são estáveis até a degradação durante o catabolismo das proteínas. O nível sérico da frutosamina depende da média da concentração da glicose durante as prévias duas semanas e a meia vida das proteínas sanguíneas, e não está sujeita a mudanças devido à hiperglicemia 
transitória (Ambruster 1987). Pode ainda ser usada como um indicador iminente da ocorrência da TP, tanto em casos isolados como em rebanhos, quando os níveis séricos de $\beta$-hidroxibutirado estão ainda dentro dos limites normais (Cantley et al. 1991, Santos et al. 2011).

A amilase encontrou-se elevada, provavelmente em função da dieta rica em carboidratos, que de acordo com Kaneko et al. (2008) estimula a síntese da amilase. De acordo com Peragón et al. (1994) a amilase é uma das enzimas digestivas, de origem no pâncreas, que age no intestino delgado sobre os polissacarídeos presentes no quimo (Peragón et al. 1994). É liberada pelo pâncreas exócrino e sua elevação parece refletir um bom funcionamento da função exócrina pancreática. Uma diminuição da amilase, não é muito rara, geralmente está associada a animais que são submetidos a dietas pobres em amido (González \& Scheffer 2002). Dados na literatura são escassos sobre o estudo dessa enzima nas espécies ruminantes, especialmente no que diz respeito ao seu envolvimento em transtornos metabólicos como a TP.

A diminuição dos níveis de cálcio pode está relacionado à maior demanda encontrada durante o final da gestação devido à mineralização fetal e/ou pela produção do colostro materno que requer quantidade considerável dos níveis circulantes do elemento. Sigurdsson (1991) verificou casos naturais de TP combinados a hipocalcemia, alertando para a semelhante apresentação clínica das duas enfermidades. Esta condição foi reafirmada por Brozos et al. (2011), acrescentando que o diagnóstico diferencial entre as duas doenças é difícil a nível de campo, e somente poderá ser concluído com segurança avaliando-se as concentrações de cálcio e $\beta$-hidroxibutirato no sangue dos animais. No entanto, parece coexistir uma relação entre hipocalcemia e a elevação dos corpos cetônicos observado pelo efeito depressivo sobre a produção endógena de glicose, e com isso facilitando o surgimento de casos de TP (Schlumbohm \& Harmeyer 2003). Já Walz et al. (2007), demonstrou a importante participação do cálcio nas diferentes fases de secreção de insulina pelas células $\beta$-pancreáticas, e essa associação foi observada por Sigurdsson (1991) ao encontrar concentrações baixas de cálcio e insulina em ovelhas com quadro de paresia durante o final de gestação. Tal fato foi constatado neste experimento, em que se observou moderada relação linear positiva $(\mathrm{r}=0,51)$ entre estes metabólitos.

Os níveis séricos de fósforo encontram-se diminuídos possivelmente em função do rápido aumento do crescimento fetal no terço final de gestação, já que de acordo com Payne (1983), assim como o cálcio, o fósforo também é um componente vital da estrutura óssea do esqueleto fetal que se combina em proporção relativamente constante, embora o fósforo se distribua de forma diferente. Enquanto o cálcio encontra-se em maior quantidade no tecido ósseo, por outro lado nos líquidos corporais há uma maior quantidade de fósforo; além de seu metabolismo não se encontrar tão regulado como acontece com o do cálcio que é fortemente ajustado por interações entre hormônios e metabólitos. Halford \& Sanson (1983) e Van Saun (2000) ao avaliarem a ocorrência de casos de TP em rebanhos de ovelhas também encontraram hipofosfatemia. No entanto, Hefnawy et al. (2011), apesar de encontrar diminuição da concentração dos níveis de fósforo em cabras com TP, esta não foi significativa em relação aos animais controle, o que corrobora com os achados de Henze et al. (1998) que constataram não haver diferença na concentração dos níveis séricos de fósforo entre ovelhas com cetose e saudáveis. Tal achado foi reiterado por Bani Ismail et al. (2008) que demonstraram não haver diferença entre cabras acometidas de forma subclinica e saudáveis.

A diminuição encontrada na concentração sérica de sódio pode está relacionada à diminuição do apetite e a diminuição da motilidade do trato gastrointestinal pelas cabras acometidas, já que o sódio, de acordo com Payne (1983), ingressa fundamentalmente no rúmen com a saliva e não com o alimento, e é ativamente absorvido segundo a concentração do gradiente eletroquímico através da parede ruminal e ao longo do tubo digestivo. Outro fator a considerar, em parte, é a falha renal que foi apontada como uma das causas de hiponatremia ocorrida em cabras acometidas por TP (Lima et al. 2012). Todavia, no início da desidratação, quantidades aumentadas de cloreto de sódio aparecem na urina enquanto se reduzem no fluido extracelular. Por isso, quando à água celular se desloca para o compartimento extracelular, há perda de potássio celular, que também é excretado na urina. Desta forma, após um período de desidratação, o animal estará desprovido tanto de água como de eletrólitos principais (Swenson \& Reece 1993). A hiponatremia encontrada também foi observada por Hefnawy et al. (2011) em cabras com TP após indução e foi relacionada a ausência da alimentação, a desidratação e ao envolvimento dos rins na patogênese da doença. Entretanto, diferiu dos achados de Henze et al. (1998) nos casos espontâneos em ovelhas com TP, e dos achados de González et al. (2012), após a indução da enfermidade em cabras, concluindo que este eletrólito não é um bom indicador para a detecção precoce da TP.

Os elementos cloro, magnésio e potássio mantiveram-se dentro dos valores de referência para a espécie. Os resultados encontrados estão de acordo com Bani Ismail et al. (2008) e González et al (2012), que não observaram diferença de concentração sérica de magnésio , cloro e potássio em cabras com TP, em relação à aquelas que não apresentavam a doença. No entanto, hipomagnesemia pode estar presente em casos de TP, embora a condição possa preceder ou ocorrer simultaneamente a enfermidade (Andrews 1997). Hipomagnesemia foi observada também por Hefnawy et al. (2011) em cabras com TP, embora não tenha sido por Henze et al. (1998) em ovelhas com TP, que por outro lado identificou valores de potássio significativamente inferiores em ovelhas com a enfermidade.

O baixo nível de insulina encontrado é relatado por Henze et al. (1998), Santos et al. (2011), Hefnawy et al. (2011) em casos de TP. Esta condição é justificada por Schmmit et al. (2011), que demonstraram em ovelhas no terço final de gestação, haver maior resistência dos tecidos periféricos à insulina, nos quais apresentam menor capacidade de metabolização da glicose e que conforme a gestação avança, a concentração materna de insulina, assim como a respos- 
ta da insulina a uma carga de glicose, é significativamente reduzida, para que tecidos que a usam como principal fonte de energia tenha prioridade por tal metabólito e mantenham sua funcionalidade como é o caso em questão: a unidade feto - placentária é a responsável pela grande demanda que é sem dúvida o principal fator envolvido no surgimento da doença nas cabras. Outro fator a considerar para os baixos índices da insulina, segundo Regnault et al. (2004), é influenciado também pelo aumento dos AGNE`s, evidenciado pela forte relação negativa ocorrida, que embora forneça a fêmea prenhe uma fonte de energia para o metabolismo materno, provoca com isso o desenvolvimento de resistência a insulina nos tecidos periféricos maternos, assim como a redução da produção da insulina, com isso a glicose é poupada e disponibilizada para o aproveitamento da placenta e para atender a demanda fetal. Tal fato, ainda não está bem definido, mas pode ser resultado das interações entre os hormônios da gestação e do pâncreas materno, como resultado da elevação crônica das concentrações dos AGNE's.

Houve significativa elevação nos níveis de cortisol encontrados nas cabras com TP, assim como os observados por Hefnawy et al. (2011), em estudo experimental em cabras, e por Ford et al. (1990) e Sigurdsson (1991) em ovelhas, cujos resultados podem ser explicados pelo aumento da produção pela adrenal ou devido a inabilidade encontrada pelo fígado gorduroso em casos de TP em metabolizar e excretar o cortisol circulante. Porém, Bani Ismail et al. (2008) não observaram diferença significativa entre o hormônio em cabras saudáveis e com TP subclínica em virtude de uma condição clínica branda nos animais acometidos. Dessa forma, o cortisol efetivamente age de maneira oposta a insulina, enquanto esta permite aos tecidos utilizar a glicose mesmo em baixas concentrações sanguíneas, o cortisol diminui a habilidade dos tecidos para utilizar a glicose nesta condição (Basset et al. 1966). Segundo Reid (1960), este efeito inibitório sobre a utilização da glicose pode ser aumentado sob condições de severa insuficiência de insulina, e a severidade da cetose depende do balanço entre cortisol e insulina, mais do que da absoluta quantidade de cada hormônio secretado, desta forma o grau de inibição da utilização da glicose e o aparecimento dos sinais clínicos podem depender deste equilíbrio.

\section{CONCLUSÕES}

Acentuadas alterações clínicas e metabólicas são observadas em cabras acometidas com a toxemia da prenhez (TP), na qual os transtornos de certos metabólitos relacionados ao perfil bioquímico, eletrolítico e hormonal como $\beta$-hidroxibutirato, AGNE's, ureia, creatinina, cálcio total, cálcio ionizado, insulina e cortisol são importantes ferramentas para o diagnóstico e constitui um bom instrumento para avaliar a magnitude da condição clínica dos animais enfermos.

Os dados encontrados servem de referência para estudos sobre nutrição e metabolismo em cabras com TP e podem contribuir para o diagnóstico diferencial de outras enfermidades metabólicas que ocorrem no período de transição.
Agradecimentos.- À Fundação de Amparo à Pesquisa do Estado de Pernambuco (FACEPE) pela concessão da Bolsa de Mestrado, à Clínica de Bovinos, Campus Garanhuns, UFRPE, pelo apoio na realização deste trabalho e à CAPES pelo projeto aprovado no edital Programa Nacional de Pós-Doutorado, PNPD/2011.

\section{REFERÊNCIAS}

Almeida M.Z.P.R.B., Mendonça C.L., Afonso J.A.B. \& Miranda Neto E.G. 2008. Estudo clínico, hematológico e bioquímico em caprinos submetidos à acidose láctica ruminal induzida experimentalmente. Vet. Zootec. 15(1):100-3.

Ambruster D.A. 1987. Fructosamine: structure, analysis, and clinical usefulness. Clin. Chem. 33:2153-2163.

Andrews A. 1997. Pregnancy toxaemia in the ewe. In Practice. 19:306-312.

Araújo D.F. \& Silva I.P. 2008. Valores de amilase, glicose, colesterol e triglicérides em soro de cabras de Mossoró, RN. Acta Veterinaria Brasilica 2(3):97-100.

Bani Ismail Z.A., Al Majali A.M., Amireh F. \& Al-Rawashdeh O.F. 2008. Metabolic profiles in goat does in late pregnancy with and without subclinical pregnancy toxemia. Vet, Clin. Pathol., Irbid, Jordan, 4(37):434-437.

Barakat S.E.M., AL-Bhanasawi N.M., Elazhari G.E. \& Bakhiet A.O. 2007. Clinical and serobiochemical studies on naturally - ocurring pregnancy toxaemia in Shamia goats. J. Anim. Vet. Adv. 6(6):768-772.

Barioni G., Fonteque J.H., Paes P.R.O., Takahira R.K., Kohayagawa A., Lopes R.S., Lopes S.T.A. \& Crocci A.J. 2001. Valores séricos de cálcio, fósforo, sódio, potássio e proteínas totais em caprinos fêmeas da raça parda alpina. Ciência Rural 31(3):435-438.

Bassett J.M., Mills S.C. \& Reid R.L. 1966. The influence of cortisol on glucose utilization in sheep. Metabolism 15(10):922-932.

Borges J.R.J., Godoy R.F., Ximenes F.B., Castro M.B., Mustafa V., Reckziegel G. \& Novais E.B.F. 2009. Doenças hepáticas em ovinos e caprinos. Anais VIII Congresso Brasileiro de Buiatria, Belo Horizonte. Ciênc. Anim. Bras. 1(Supl.).

Brozos C., Mavrogianni V.S. \& Fthenakis G.C. 2011. Treatment and control of peri-parturient metabolic diseases: pregnancy toxemia, hypocalcemia, hypomagnesemia. Vet. Clin. Food Anim. 27:105-113.

Cal L., Borteiro C., Benech A., Rodas E., Abreu M.N., Cruz J.C. \& González Montaña J.R. 2009. Histological changes of the liver and metabolic correlates in ewes with pregnancy toxemia. Arq. Bras. Med. Vet. Zootec. 61(2):306-312.

Campos A.G.S., Afonso J.A.B., Santos R.A., Mendonça C.L. \& Guimarães J.A. 2010. Estudo clínico-laboratorial da toxemia da prenhez em ovelhas: análise retrospectiva. Ciênc. Anim. Bras. 11(3):623-628.

Cantley C.E.L., Ford C.M. \& Heath M.F. 1991. Serum fructosamine in ovine pregnancy: a possible prognostic index. Vet. Rec. 128(6):525-526.

Cerón J.J., García Partida P., Sotillo J., Bayón A. \& Gutiérrez Panizo C. 1994. Serum protein and protein electrophoretic pattern variations in goats with ketosis during various stages of reproduction. XVIII World Buiatrics Congress, Proc. XXVII Congress of the Italian Association of Buiatrics, 99:1309-1313.

Dirksen G., Gründer H.-D. \& Stöber M. 1993. Rosenberger, Exame Clínico dos Bovinos. 3a ed. Guanabara Koogan, Rio de Janeiro. 419p.

Firat A. \& Özpinar A. 2002. Metabolic profile of pre-pregnancy, pregnancy and early lactation in multiple lambing Sakiz ewes. Annals of Nutrition and Metabolism, Istanbul, 46:57-61.

Ford E.J.H., Evans J. \& Robinson I. 1990. Cortisol in pregnancy toxaemia of sheep. Brit. Vet. J. 146(6):539-542.

González F.H.D. \& Scheffer J.F.S. 2002. Perfil sanguíneo: ferramenta de análise clínica, metabólica e nutricional, Anais 29 Conbravet, Gramado, RS, p.5. (Resumo)

González F.H.D \& Silva S.C. 2006. Introdução à Bioquímica Clínica Veterinária. UFRGS, Porto Alegre. 357p.

González F.H.D., Barcellos J.O., Patiño H.O. \& Ribeiro L.A. 2000. Perfil metabólico em ruminantes: seu uso em nutrição e doenças nutricionais. Gráfica da Universidade Federal do Rio Grande do Sul, Porto Alegre. 108p.

González F., Muiño R., Pereira V., Campos R. \& Castellote J.L.B. 2009. Indicadores sanguíneos de lipomobilização e função hepática no início da lactação em vacas leiteiras de alta produção. Anais VIII Congresso Brasileiro de Buiatria, Belo Horizonte. Ciênc. Anim. Bras. 1:64-69.

González F.H.D., Muiño R., Pereira V., Campos R. \& Benedito J.L. 2011a. Relationship among blood indicators of lipomobilization and hepatic 
function during early lactation in high-yielding dairy cows. J. Vet. Sci. 3:251-255.

González F.H.D., Hernández F., Madrid J., Martínez-Subiela S., Tvarijonaviciute A., Céron J.J. \& Tecles F. 2011b. Acute phase proteins in experimentally induced pregnancy toxemia in goats. J. Vet. Diagn. Invest. 23:57-62.

González F.H.D., Hernández F., Madrid J., Martínez-Subiela S., Cerón J.J. \& Tecles F. 2012. Acid-base and electrolyte status during early induced pregnancy toxaemia in goats. Vet. Journal 193:598-599.

Hallford D.M. \& Sanson D.W. 1983. Serum profiles determined during ovine pregnancy toxemia. Agri. Pract. 4:27-33.

Harmeyer J. \& Schlumbohm C. 2006. Pregnancy impairs ketone body disposal in late gestating ewes: implications for onset of pregnancy toxemia. Vet. Sci. 81:254-264.

Hefnawy A.E., Shousha S. \& Youssef S. 2011. Hematobiochemical profile of pregnant and experimentally pregnancy toxemic goats. J. Basic Appl. Chem., Egypt, 1:65-69.

Henze P., Bickhardt K., Fuhrmann H. \& Sallmann H.P. 1998. Spontaneous pregnancy toaxemia (Ketosis) in sheep and the role of insulin. J. Am. Vet. Med. Assoc. 45:225-226.

Kaneko J.J., Harvey J.W. \& Bruss M.L. 2008. Clinical Biochemistry of Domestic Animals. $6^{\text {th }}$ ed. Academic Press, San Diego. 916p.

Lima M.S., Pascoal R.A. \& Stilwell G.T. 2012. Glycaemia as a sign of the viability of the foetuses in the last days of gestation in dairygoats with pregnancy toxaemia. Irish Vet. Journal 1(65).

Little T.M. \& Hills F.J. 1978. Agricultural Experimentation: design and analysis. John Wiley, New York. 350p.

Metz S.H.M., Mulder I. \& Van Den Bergh S.G. 1973. Regulation of lipolysis in bovine adipose adipose tissue by the degree of saturation of plasma albumin with fatty acids. Biochimica et Biophysica Acta, Amsterdam, 306:42-50.

Mobini S., Heath A.M. \& Pugh D.G. 2005. Teriogenologia de Ovinos e Caprinos, p. 145-208. In: Pugh D.G. (Ed.), Clínica de Ovinos e Caprinos. Roca, São Paulo.

Moghaddam G. \& Hassanpour A. 2008. Comparison of blood serum glucose, beta hidroxybutiric acid, blood urea nitrogen and calcium concentrations in pregnant and lambed ewes. J. Anim. Vet. Adv. 7(3):308-311.

Ortolani E.L. 2004. Toxemia da prenhez em pequenos ruminantes: como reconhecê-la e evitá-la. Disponível em <http// www.br.monografias. com> Acesso em 11 dez. 2004.

Parry H.B. \& Taylor W.H. 1956. Renal function in sheep during normal and toxaemic pregnancies. J. Physiol. 131:383-392.

Payne J.M. 1983. Enfermedades metabolicas de lós animales zootecnicos. Editorial Acribia, Zaragoza. 218p.

Peragón J., Barroso J.B., Garcia-Salgueiro L., Higuera M. \& Lupianez J.A. 1994. Dietary protein effects on growth and fractional protein synthesis and degradation rates in liver and white muscle of rainbow trout (Oncorhynchus mykiss). Aquaculture 124:35-46.

Regnault T.R.H., Oddy H.V., Nancarrow C., Sriskandarajad N. \& Scaramuzzi R.J. 2004. Glucose - stimulated insulin response in pregnant sheep following acute suppression of plasma non-sterifield fatty acid concentrations. Rep. Biol. Endocrinol. 2(64):1-10.

Reid R.L. 1960. Studies on the carbohydrate metabolism of sheep. Aust. J. Agric. Res. 11(3):364-382.

Rios C., Marín M.P., Catafau M. \& Wittwer F. 2006. Concentraciones sanguíneas de $\beta$ - hidroxibutirato, NEFA, colesterol y urea en cabras lecheras de três rebaños com sistemas intensivos de producción y surelaciónconel balance nutricional. Arch. Med. Vet. 38(1):19-23.

Rook J.S. 2000. Pregnancy toxemia of ewes, does, and beef cows. Vet. Clin. North Am., Food Anim. Pract. 16(2):293-317.

Santos F.C.O., Mendonça C.L., Silva Filho A.P., Carvalho C.C.D., Soares P.C. \& Afonso J.A.B. 2011. Indicadores bioquímicos e hormonais de casos naturais de toxemia da prenhez em ovelhas. Pesq. Vet. Bras. 31(11):974-980.

Sargison N.D., Scott P.R., Penny C.D., Pirie R.S. \& Kelly J.M. 1994. Plasma enzymes and metabolites as potential prognostic indices of ovine pregnancy toxaemia: a preliminary study. Brit. Vet. J. 150:271-277.

Schlumbohm C. \& Harmeyer J. 2003. Hipocalcemia reduces endogenous glucose production in hiperketonemic sheep. J. Dairy Sci. 86:1953-1962.

Schlumbohm C. \& Harmeyer J. 2008. Twin-pregnancy increases susceptibility of ewes to hypoglycaemic stress and pregnancy toxemia. Res. Vet. Sci. 84:286-299.

Schmitt E., Schneider A., Gourlat M.A., Schwegler E., Pereira R.A., Hoffmann D.C.A., Lopes M.S., Hax L.T., Del Pino F.A.B. \& Corrêa M.N. 2012. Correlação entre cálcio e insulina durante o teste de tolerância à glicose em ovelhas gestantes e não gestantes. Arq. Bras. Med. Vet. Zootec. 64(5):1127-1132.

Scott P.R., Sargison N.D., Penny C.D., Pirie R.S. \& Kelly J.M. 1995. Cerebrospinal fluid and plasma glucose concentrations of ovine pregnancy toxaemia cases, inappetant ewes and normal ewes during late gestation. Brit. Vet. J. 151:39-44.

Sigurdsson H. 1991. Metabolic disorders in ewes during late pregnancy. Iceland Agric. Sci. 5:25-31.

Smith M.C. \& Sherman D.M. 2009. Goat Medicine. $2^{\text {nd }}$ ed. Lea and Febiger, Philadelphia. 871p.

Swenson M. \& Reece W. 1996. Duke's Fisiologia dos Animais Domésticos. $11^{\mathrm{a}}$ ed. Guanabara Koogan, Rio de Janeiro. 856p.

Van Saun R.J. 2000. Pregnancy toxemia in a flock of sheep. J. Am. Vet. Med. Assoc. 21(10):1536-1539.

Walz H.A., Wierup N. \& Vikman J. 2007. $\beta$-cell PDE3B regulates Ca $2+$ stimulated exocytosis of insulin. Cell Signalling 19:1505-1513.

Yarim G.F. \& Ciftci G. 2009. Serum protein pattern in ewe with pregnancy toxemia. Vet. Res. Commun. 33:431-438. 